\title{
Platelet kinetics in asthmatic patients with and without aspirin intolerance
}

\author{
V Plaza, F Casals, A Alonso, C Picado
}

\begin{abstract}
Background A reduced platelet survival time has been described in asthmatic patients. There is also good evidence that platelets are involved in aspirin induced asthma. Since aspirin intolerant patients usually suffer from an active disease and often require antiinflammatory treatment, it has been suggested that platelet survival time may be shorter in aspirin intolerant asthmatic subjects than in aspirin tolerant subjects. The objective of this study was to investigate this hypothesis.

Methods Thirteen asthmatic subjects (six aspirin tolerant and seven aspirin intolerant) in a stable clinical condition and ten healthy subjects were studied. Platelet kinetics and survival time were measured with indium-111 labelled autologous platelets.

Results Mean (SD) platelet sequestration ratios in the spleen and liver were lower in asthmatic $(2.3(0.9)$ and $0.6(0.2)$ respectively) than in healthy subjects $(3 \cdot 2$ $(0.7)$ and $1.1(0.4)$ respectively). However, mean (SD) platelet survival time in asthmatic subjects $(8(2 \cdot 7)$ days) did not differ from that in healthy subjects $(7 \cdot 6(1 \cdot 1)$ days). No differences were observed in platelet kinetics between aspirin tolerant and aspirin intolerant patients.

Conclusions These results suggest the existence of an active non-splenic pool of platelets in patients with asthma. However, they failed to show platelet kinetic differences among asthmatic subjects with and without aspirin intolerance and do not support previous studies suggesting an altered platelet survival in stable asthma.
\end{abstract}

In the last ten years studies have suggested that platelets are involved in inflammatory phenomena, ${ }^{1-3}$ including bronchial asthma. ${ }^{4-11}$ Disturbances of haemostasis ${ }^{12}$ and altered platelet serotonin uptake ${ }^{13}$ have also been reported in asthmatic patients. Taytard et $a l^{14}$ described a shortened platelet survival time in nine asthmatic patients suggesting that platelets are destroyed faster in those with asthma than in a healthy population. Since this shortened survival time may be reversed when the patients are treated with steroids, it has been suggested that the accelerated destruction of platelets in asthmatics may be directly related to the inflammatory activity of the disease.
Platelets also seem to have a pivotal role in the pathogenesis of asthma attacks precipitated by aspirin (acetylsalicylic acid) and other nonsteroidal anti-inflammatory drugs (NSAIDs). The hypothesis that platelets have a role in aspirin sensitive asthma is supported by the observations of Ameisen et al, who found that when platelets from aspirin intolerant asthmatics were incubated with acetylsalicylic acid there was a release of oxygen free radicals. This contrasts with the platelet reaction in aspirin tolerant patients who showed no such response. ${ }^{1516}$ We reasoned that if platelets are involved in aspirin induced asthma, this peculiar group of patients might also differ from aspirin tolerant asthmatics with respect to platelet kinetics. Since aspirin intolerant patients often suffer from a persistent process which usually requires regular anti-inflammatory treatment (inhaled and oral steroids), we hypothesised that platelet survival might be shorter in these patients than in aspirin tolerant subjects. The objective of the present study was to test this hypothesis.

\section{Subjects and methods}

\section{SUBJECTS}

Twenty three subjects were studied, divided into two groups: ten healthy volunteers (group 1) and 13 asthmatics (group 2), six of whom were aspirin tolerant and seven aspirin intolerant. Characteristics of the population are depicted in table 1. All asthmatic subjects satisfied the American Thoracic Society criteria for bronchial asthma ${ }^{17}$ and attended the outpatient clinic of our hospital. Aspirin intolerant asthmatic patients showed a clear clinical history of one or more asthma attacks precipitated by NSAIDs. Three patients needed hospital admission and one of them required mechanical ventilation. The study was carried out while the asthmatic patients were in a stable clinical condition and at least three months after their last asthma attack. None of the patients was receiving treatment with oral steroids. All asthmatic patients were receiving inhaled adrenergic agents (salbutamol or terbutaline) and three were also on regular oral theophylline. Eleven patients were treated with inhaled budesonide (table 1). The subjects gave informed and signed consent to participate in the study, which had been approved by the Research Committee. The control group included healthy volunteers not receiving any treatment. 
Table 1 Mean (SD) clinical and spirometric characteristics of subjects

\begin{tabular}{llccc}
\hline & Controls & $\begin{array}{l}\text { Aspirin } \\
\text { tolerant }\end{array}$ & $\begin{array}{l}\text { Aspirin } \\
\text { intolerant }\end{array}$ & All asthmatics \\
\hline No of patients & 10 & 6 & 7 & 13 \\
Age (years) & $37 \cdot 2(16)$ & $48 \cdot 1(18)$ & $55 \cdot 6(7 \cdot 3)$ & $52(14 \cdot 2)$ \\
Male:female & $4: 6$ & $4: 2$ & $3: 4$ & $7: 6$ \\
Smokers & 4 & 2 & 0 & 2 \\
Nasal polyps & 0 & 2 & 3 & 5 \\
Years of asthma & - & $20 \cdot 2(16)$ & $16 \cdot 8(10)$ & $18 \cdot 4(12 \cdot 7)$ \\
FEV $(\%$ predicted) & - & $75(24)$ & $82(14)$ & $78 \cdot 8(18 \cdot 5)$ \\
BD-FEV $(\%)$ & - & $14 \cdot 8(9 \cdot 8)$ & $8 \cdot 8(5 \cdot 3)$ & $11 \cdot 5(7 \cdot 9)$ \\
Positive prick test response & - & 6 & $1 \star$ & 7 \\
Eosinophils in blood $\left(\times 10^{9} / 1\right)$ & - & $0 \cdot 152(0 \cdot 08)$ & $0 \cdot 403(0 \cdot 26)$ & $0 \cdot 309(0 \cdot 24)$ \\
Inhaled budesonide & - & 4 & 7 & 11 \\
Budesonide $(\mu$ g/day) & $1200(462)$ & $1085(381)$ & $1140(393)$ \\
\hline
\end{tabular}

${ }^{\star} \mathrm{p}<0.05$ compared with aspirin tolerant group ( $\chi^{2}$ test).

FEV ${ }_{1}$ - forced expiratory volume in one second; \%BD-FEV ${ }_{1}$-bronchodilatation in terms of $\mathrm{FEV}_{1}$ after two puffs of salbutamol.

\section{PLATELET LABELLING}

Platelet labelling was performed in plastic containers. Whole blood was drawn through a short 19 gauge needle into a plastic syringe and transferred to conical plastic tubes containing anticoagulant. Platelet rich plasma was obtained by centrifugation at $200 \mathrm{~g}$ for 15 minutes and transferred to $10 \mathrm{ml}$ tubes. The platelet rich plasma was centrifugated and a cell pellet obtained. The cell pellet was resuspended in a human albumin/saline solution with low $\mathrm{pH}$ and normal osmolarity. After a new washing procedure the platelets were incubated with $150 \mu \mathrm{Ci}$ of indium-111 labelled oxine solution (Amersham). The cells were repelleted and the supernatant removed. Finally, the labelled platelets were resuspended in platelet poor plasma and reinjected.

PLATELET RECOVERY AND SURVIVAL

At 15 minutes after the injection a blood sample was taken from the side opposite the injection site for the calculation of platelet recovery. The whole blood volume was measured by iodine125 labelled albumin dilution test. For computing platelet recovery, the formula described by Paulus was employed. ${ }^{18}$

Platelet survival curves were constructed from blood samples taken at intervals over the following 10 days; a gamma function was fitted over the experimental points following the recommendations of the Standardization Committee of the International Society of Hematology. ${ }^{19}$

QUANTITATION OF LIVER AND SPLEEN INDICES Quantification of liver and spleen radioactivity indices was performed with a gamma camera. Upon entering the spleen, about one half of all platelets become trapped in the microvasculature; a fraction is retained permanently, while the rest return to the circulation after a slow transit time. These intrasplenic kinetics predict the bioexponential clearance curve. After resolution of the clearance curve, the rate constants and platelet splenic pool were calculated with the two components platelet retention and platelet destruction. ${ }^{20} \mathrm{~A}$ double exponential curve was fitted with the experimental points found during a one hour exploration. The ratio between geometric mean for splenic counts (anterior and posterior) and heart or liver was computed at one, 24 and 48 hours.

\section{ANALYSIS}

Analysis of variance and Kruskal-Wallis tests were used to evaluate differences among the three groups. The Mann-Whitney test was used to assess differences between the two groups and the $\chi^{2}$ test was also used when appropriate. The level of significance in all tests was $\mathrm{p}<0.05$.

\section{Results}

There were no differences between aspirin tolerant and aspirin intolerant patients with respect to airways obstruction. A higher proportion of aspirin sensitive patients than aspirin tolerant asthmatic patients were receiving treatment with inhaled steroids, but the difference was not significant. As expected the proportion of aspirin intolerant patients suffering from nasal polyps was higher than the proportion in the aspirin tolerant group. The percentage of aspirin intolerant patients with a positive prick test was significantly lower than the percentage of aspirin tolerant asthmatics (table 1).

The platlet kinetic results for controls and the two groups of asthmatics are shown in table 2. No differences were found in total platelet counts between the asthmatic and control groups. No differences were found in survival time, transit time and splenic blood flow between healthy and asthmatic subjects. Although the two asthmatic groups showed a smaller percentage recovery and higher turnover levels than healthy subjects, the differences were not significant.

A comparison between healthy and asthmatic subjects showed that hepatic and spleen capture was significantly lower in patients than in the control group ( $p<0.05$ for liver:heart ratio and $p<0.02$ for spleen:heart ratio). A significantly lower hepatic and splenic capture (liver:heart and spleen:heart ratios) was also observed in both aspirin tolerant $(p=0.025$ and $p=0.05$ respectively, Mann-Whitney test) and aspirin intolerant asthmatics ( $p<0.01$ and $p<0.05$ respectively, Mann- 
Table 2 Mean (SD) and 95\% confidence limits of platelet kinetic values

\begin{tabular}{|c|c|c|c|c|}
\hline & Controls & $\begin{array}{l}\text { Aspirin } \\
\text { tolerant }\end{array}$ & $\begin{array}{l}\text { Aspirin } \\
\text { intolerant }\end{array}$ & All asthmatics \\
\hline Platelets (number $\times 10^{9} / 1$ ) & $\begin{array}{c}137(48) \\
(114-159)\end{array}$ & $\begin{array}{c}161(48) \\
(111-212)\end{array}$ & $\begin{array}{c}141(43) \\
(104-178)\end{array}$ & $\begin{array}{c}150(43) \\
(124-177)\end{array}$ \\
\hline Survival (days) & $\begin{array}{r}7.6(1 \cdot 1) \\
(6.8-8.4)\end{array}$ & $\begin{array}{c}8 \cdot 5(3 \cdot 6) \\
(4 \cdot 7-12 \cdot 4)\end{array}$ & $\begin{array}{r}7.6(1.9) \\
(5.9-9.4)\end{array}$ & $\begin{array}{c}8(2 \cdot 7) \\
(6 \cdot 4-9 \cdot 7)\end{array}$ \\
\hline Recovery (\%) & $\begin{array}{c}48 \cdot 4(3) \\
(41 \cdot 6-55 \cdot 2)\end{array}$ & $\begin{array}{l}37 \cdot 2(6 \cdot 8) \\
(30-44 \cdot 4)\end{array}$ & $\begin{array}{r}47 \cdot 4(22 \cdot 4) \\
(26 \cdot 7-68 \cdot 1)\end{array}$ & $\begin{array}{c}42 \cdot 7(17) \\
(32 \cdot 3-53 \cdot 1)\end{array}$ \\
\hline Platelet turnover $\left(\times 10^{9} / 1 /\right.$ day $)$ & $\begin{array}{c}39(13) \\
(30-49)\end{array}$ & $\begin{array}{c}56(20) \\
(34-77)\end{array}$ & $\begin{array}{l}54(31) \\
(25-82)\end{array}$ & $\begin{array}{l}55(26) \\
(39-70)\end{array}$ \\
\hline Spleen:heart ratio & $\begin{array}{r}3 \cdot 2(0 \cdot 7) \\
(2 \cdot 5-3 \cdot 8)\end{array}$ & $\begin{array}{l}2 \cdot 2(1 \cdot 3)^{\star} \\
(0.9-3 \cdot 5)\end{array}$ & $\begin{array}{l}2.4(0.5)^{\star} \\
(1.8-2.9)\end{array}$ & $\begin{array}{l}2 \cdot 3(0 \cdot 9)^{\star} \\
(1 \cdot 7-2 \cdot 9)\end{array}$ \\
\hline Liver:heart ratio & $\begin{array}{l}1 \cdot 14(0 \cdot 4) \\
(0 \cdot 8-1 \cdot 5)\end{array}$ & $\begin{array}{l}0.6(0.3)^{\star} \\
(0.3-1)\end{array}$ & $\begin{array}{l}0.5(0.18) \dagger \\
(0.3-0.7)\end{array}$ & $\begin{array}{l}0.6(0.2)^{\star} \\
(0.4-0.7)\end{array}$ \\
\hline Transit time (minutes) & $\begin{array}{l}8 \cdot 6(0 \cdot 8) \\
(7 \cdot 7-9 \cdot 5)\end{array}$ & $\begin{array}{l}8 \cdot 1(2 \cdot 7) \\
(5 \cdot 2-11)\end{array}$ & $\begin{array}{r}15.5(19 \cdot 8) \\
(-5.4-36 \cdot 3)\end{array}$ & $\begin{array}{l}11 \cdot 7(14) \\
(2 \cdot 8-20 \cdot 7)\end{array}$ \\
\hline Splenic blood flow (ml/minute) & $\begin{array}{c}331 \cdot 7(91) \\
(236 \cdot 2-427)\end{array}$ & $\begin{array}{c}271 \cdot 1(94) \\
(154 \cdot 5-387 \cdot 6)\end{array}$ & $\begin{array}{r}329 \cdot 3(122 \cdot 2) \\
(177 \cdot 6-481 \cdot 1)\end{array}$ & $\begin{array}{c}300 \cdot 2(107) \\
(223 \cdot 5-376 \cdot 9)\end{array}$ \\
\hline Spleen destruction (\%) & $\begin{array}{c}2.1(1.5) \\
(0.23-3.9)\end{array}$ & $\begin{array}{c}0.23(0.3) \\
(-0.1-0.6)\end{array}$ & $\begin{array}{c}0.34(0.5) \\
(-0.2-0.9)\end{array}$ & $\begin{array}{c}0.28(0.4)^{\star} \\
(0.01-0.5)\end{array}$ \\
\hline Spleen:liver ratio at 1 hour & $\begin{array}{l}3 \cdot 2(0 \cdot 9) \\
(2 \cdot 5-4)\end{array}$ & $\begin{array}{l}3 \cdot 6(1 \cdot 2) \\
(2 \cdot 1-5)\end{array}$ & $\begin{array}{l}4 \cdot 6(2 \cdot 6) \\
(2 \cdot 2-7)\end{array}$ & $\begin{array}{c}4 \cdot 1(2 \cdot 1) \\
(2 \cdot 8-5 \cdot 5)\end{array}$ \\
\hline Spleen:liver ration at 24 hours & $\begin{array}{c}3 \cdot 8(1 \cdot 1) \\
(2 \cdot 9-4 \cdot 8)\end{array}$ & $\begin{array}{c}4 \cdot 4(1 \cdot 7) \\
(1 \cdot 6-7 \cdot 1)\end{array}$ & $\begin{array}{c}3 \cdot 8(1) \\
(2 \cdot 9-4 \cdot 7)\end{array}$ & $\begin{array}{l}4 \cdot 04(1 \cdot 2) \\
(3 \cdot 2-4 \cdot 8)\end{array}$ \\
\hline
\end{tabular}

${ }^{\star} \mathrm{p}<0.05 ; \mathrm{p} p<0.01$ compared with controls.

Whitney test) with respect to controls. Moreover, all asthmatic subjects taken together showed a significantly lower splenic destruction than controls $(p<0.05)$. When the comparison was made between each group of patients and the control group, the difference was not significant.

No significant differences were found in any of the indices studied between aspirin tolerant and aspirin intolerant asthmatic subjects.

\section{Discussion}

The most relevant findings of our study are the following: platelet survival in asthmatics did not differ from that in healthy subjects, despite the fact that platelet sequestration in the spleen and liver was lower in the asthmatic than in the healthy subjects. Although platelets seem to be concerned in aspirin induced asthma, there was no difference in platelet survival between aspirin tolerant and aspirin intolerant patients.

These results suggest that platelets must be sequestrated somewhere in asthmatic patients (other than in the liver and spleen) at a higher rate than in healthy subjects. The lungs might be the place where this occurs. Unfortunately, we did not measure platelet destruction in the lung so this hypothesis cannot be substantiated.

Only three studies have measured pulmonary platelet transit in asthma. One of these was carried out in stable asthmatic subjects by Taytard et al, who found a prolonged pulmonary platelet half life in asthmatic compared with healthy subjects, but the difference was not significant. ${ }^{14}$ In the other two studies, no changes in pulmonary platelet transit time could be detected in a limited number of patients after an allergen challenge. ${ }^{2122}$

Our results are at variance with those of Taytard et al, who found a shorter platelet survival time in asthmatic than in healthy subjects. One intriguing finding of the Taytard study was the presence of two different platelet populations in asthmatic patients, one with a very short life span of only 23 hours. These researchers, however, could not find the place where the platelets with a shorter survival were destroyed. Since no increase in spleen, liver and lung destruction was detected, they could not offer any explanation for this unexpected finding. Might differences in the population studied be responsible for the discrepant results? According to the description of Taytard et al, the patients included in their study suffered from a mild to moderate asthma similar to that of our patients. In both studies, patients receiving treatment with oral steroids were excluded. In our study, however, patients receiving inhaled steroids were not excluded; in Tayard's study inhaled steroids are not mentioned. Although it is generally accepted that inhaled steroids are devoid of systemic effects, it may be that the anti-inflammatory effects of these drugs on the bronchial epithelium could have diminished the release of proinflammatory substances (such as cytokines and platelet activating factor), thereby reducing the activation and recruitment of cells, including the platelets, participating in the asthmatic process. Since we do not know the potential capacity of inhaled steroids in restoring a hypothetical platelet survival disorder, we do not know if the use of this treatment in some of our patients may account for discrepancies between the studies. As only two of our asthmatics were not on inhaled steroid treatment, we could not evaluate the effect of this treatment on platelet survival.

Differences in the method used to measure platelet survival times might account for discrepancies between the study by Taytard et al and our study. Taytard computed the platelet survival time by extrapolation of the survival curve to eight to ten days after three experimental days on arithmetical or logarithmic paper. This computing method has a high level of associated error as it is a computer simulation study with only three sampling days, irrespective of the life expectancy. ${ }^{18}$ On 
the other hand, the above error is increased by the high variability introduced when only one blood tube is taken by sampling. ${ }^{20}$ Finally, fitting only the experimental points to the same established mathematical function is a valuable and reliable method for platelet survival expression. One exception to the above assertion is to compute the platelet survival time by applying the tangent to time zero directly over the experimental points plotted on graph paper, when more than eight days are employed. ${ }^{18}$

In conclusion, our study shows a normal platelet survival time despite an altered rate of spleen and liver platelet destruction in asthmatic patients. This destruction is not exclusive to a specific group of asthmatic patients, but is present in aspirin tolerant and aspirin intolerant patients. The question remains, however, of where platelets go to die in asthmatic patients.

This study was supported by a grant from CAICYT (PB 86/0594) and grant FI from Generalitat Catalunya (89).

1 Hilgard P. Blood platelets and tumour dissemination. In Jamieson GA, Scipio A, eds. Interaction of platelets and tumor cells. New York: Liss, 1982:143-58.

2 Page CP. The involvement of platelets in non-thrombotic processes. TIPS 1988;9:66-71

3 Weksler BB. Roles for human platelets in inflammation. In: Jamieson GA, ed. Platelet membrane receptors. Molecular biology, immunology, biochemistry, and pathology. New York: Alan R Liss 1988:611-38.

4 Morley J, Sanjar S, Page CP. The platelet in asthma. Lance $1984 ;$;i: $1142-4$

5 Page CP, Paul W, Basran GS, Morley J. Platelet activation in asthma. In: Weiss E, Segale M, Stein M, eds. Bronchial Asthma. Mechanisms and Therapeutics. 2nd edn. Boston: Little, Brown 1985;24:266-9.

6 Gresele P, Tdisco T, Merante F,Nenci G. Platelet activation and allergic asthma. $N$ Engl J Med 1982;306:549 (letter).

7 Metzger WJ, Sjoerdsma K, Richerson HB, Moseley P, Zavala D, Monick M, et al. Platelets in bronchoalveolar lavage from asthmatic patients and allergic rabbits with allergen-induced late phase responses. In: SchmitzSchumann $M$, Menz G, Page CP, eds. $P A F$, platelets and asthma. AAS 21. Basel: Brune, Erlangen, 1987:151-9.

8 Knauer KA, Fish JE, Adkinson NF, Lichtenstein L, Peter $\mathrm{S}$, Newball H. Platelet activation in asthma. $N$ Engl J Med 1981;305:893 (letter).

9 Knauer KA, Lichtenstein LM, Adkinson NF, Fish JE. Platelet activation during antigen-induced airway reactions in asthmatic subjects. $N$ Engl $J$ Med 1981;304: 1404-7.

10 Thompson PJ, Hanson JM, Bilani H, Turner-Warwick $M$ Morley J. Platelets, platelet activating factor and asthma. Am Rev Respir Dis 1984;129:A3.

11 Morrison JFJ, Pearson SB, Deam HG, Craig JR, Bramley N. Platelet activation in nocturnal asthma. Thorax 1991;46:197-200.

12 Kowalski ML, Grzelewska-Rzymowska I, Szmidt $M$, Rozniecki J, Bednarowicz A. Fibrinolysis, blood coagulation, and platelet function during aspirin-induced bronchoconstriction in aspirin-intolerant asthmatics. Ann Allergy 1987;58:367-71.

13 Malmgren R, Olsson P, Tornling G, Unge G. Acetylsalicylic asthma and migraine. A defect in serotonin (59HT) uptake in platelets. Thromb Res 1978;13:1137-9.

14 Taytard A, Guenard H, Vuillemin L, Bouvot JL, Vergeret J, Ducassou D, et al. Platelet kinetics in stable atopic asthmatic patients. Am Rev Respir Dis 1986;134:983-5.

15 Ameisen JC, Capron A, Joseph M, Maclouf J, Vorug H, Pancré V, et al. Aspirin-sensitive asthma: abnormal platelet response to drugs inducing asthmatic attacks. In Arch Allergy Appl Immunol 1985;78:438-48.

16 Ameisen JC, Capron A. Aspirin-sensitive asthma. Clin Exp Allergy 1990;20:127-9.

17 American Thoracic Society Committee on Diagnostic Standards for Nontuberculous Diseases. Definitions and classification of chronic bronchitis, asthma and pulmonary emphysema. Am Rev Respir Dis 1962;85:762-8.

18 Paulus JM. Destruction des plaquettes sanguines. In: Production et destruction des plaquettes sanguines. Paris: Production et destruction

19 International Committee Standardization of Haematology. The panel on diagnostic applications of radioisotopes in haematology: recommended methods for radioisotope platelet survival studies. Blood 1977;50:1137-8.

20 Casals F. Measurement of irreversible platelet destruction by the spleen in idiopathic thrombocytopenic purpura (ITP). Thromb Haemost 1985;54:129.

21 Ind PW, Peters AM, Malik F, Lavender JP, Dollery CT Pulmonary platelet kinetics in asthma. Thorax $1985 ; 40$ 412-17.

22 Hemmendinger $S$, Pauli G, Tenabene A, Pujol JL, Bessot JC, Eber M, et al. Platelet function: aggregation by PAF or sequestration in lung is not modified during immediate or late allergen-induced bronch
Clin Immunol 1989;83:990-6. 